\title{
MICRONUTRIENT INTAKES AFFECT EARLY GROWTH IN EXTREMELY PRETERM INFANTS: PRELIMINARY RESULTS FROM A SWEDISH COHORT
}

E. Stoltz Sjöström ${ }^{1}$, E.A. Szymlek-Gay ${ }^{1}$, I. Öhlund ${ }^{1}$, F. Ahlsson ${ }^{2}$, M. Norman ${ }^{3}$, E. Engström ${ }^{4}$, A. Hellström$^{4}$, V. Fellman ${ }^{5}$, E. Olhager ${ }^{6}$, M. Domellöf ${ }^{1}$

${ }^{1}$ Department of Clinical Sciences, Pediatrics, Umeå University, Umeå, ${ }^{2}$ Department of Women's and Children's Health, Uppsala University, Uppsala, ${ }^{3}$ Department of Clinical Science, Intervention \& Technology, Karolinska Institute, Stockholm, ${ }^{4}$ Institute of Clinical Sciences, Section for the Health of Women and Children, Sahlgrenska University, Gothenburg, ${ }^{5}$ Department of Pediatrics, Clinical Sciences Lund, Lund University, Lund, ${ }^{6}$ Department of Pediatrics, Linköping University, Linköping, Sweden

Background: Extremely preterm infants generally experience postnatal growth failure. It is still unclear if this is related to micronutrient intakes.

Aim: To investigate the effect of micronutrient intakes (calcium, zinc, iron, phosphorus, sodium, potassium, chloride, magnesium, vitamin A, vitamin D, vitamin E, folate and vitamin B12) on growth during the first 28 days of life in extremely preterm infants.

Method: From the EXPRESS cohort (all infants born $<27$ gestational weeks between 2004-2007 in Sweden), those who survived the first 28 days were included $(n=524)$. Daily parenteral and enteral intakes and anthropometric measurements were retrieved from hospital records.

Results: Preliminary analyses of data from 333 infants (mean \pm SD gestational age $25.2 \pm 1.0$ weeks, birth weight $753 \pm 168 \mathrm{~g}$ ) showed that macronutrient intakes were lower than recommended (energy $98 \pm 13 \mathrm{kcal} / \mathrm{kg} /$ day, protein $2.9 \pm 0.4 \mathrm{~g} / \mathrm{kg} /$ day). Infants showed postnatal growth failure: mean standard deviation scores decreased by 2.2 for weight, 2.3 for length and 1.4 for head circumference. Intakes of micronutrients were generally low, e.g. adjusted enteral intakes of calcium were $66.6 \pm 21.4 \mathrm{mg} / \mathrm{kg} / \mathrm{day}$. The exception was iron, with a high parenteral intake of $2.7 \pm 1.6 \mathrm{mg} / \mathrm{kg} / \mathrm{day}$, mainly from blood transfusions. Adjusting for protein intake and other confounders, calcium intakes were positively correlated with head growth $(\mathrm{r}=+0.19, \mathrm{p}=0.006)$ and iron intakes were negatively correlated with length gain $(\mathrm{r}=-0.18, \mathrm{p}=0.009)$.

Conclusions: Low calcium intakes and high iron intakes were associated with poor growth with regard to head circumference and length, respectively. If these results are confirmed, optimized micronutrient intakes may improve early growth in extremely preterm infants. 